\title{
8
}

\section{im

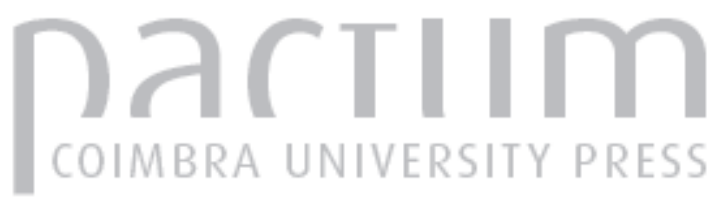

\section{Um futuro sempre presente: a continuidade da missão da Biblioteca Nacional de Portugal}

\author{
Autor(es): $\quad$ Cabral, Maria Luísa
}

Publicado por: Imprensa da Universidade de Coimbra

URL persistente:

URI:http://hdl.handle.net/10316.2/43075

DOI:

DOI:http://dx.doi.org/10.14195/0870-4112_3-3_7

Accessed : $\quad$ 26-Apr-2023 10:29:56

A navegação consulta e descarregamento dos títulos inseridos nas Bibliotecas Digitais UC Digitalis, UC Pombalina e UC Impactum, pressupõem a aceitação plena e sem reservas dos Termos e Condições de Uso destas Bibliotecas Digitais, disponíveis em https://digitalis.uc.pt/pt-pt/termos.

Conforme exposto nos referidos Termos e Condições de Uso, o descarregamento de títulos de acesso restrito requer uma licença válida de autorização devendo o utilizador aceder ao(s) documento(s) a partir de um endereço de IP da instituição detentora da supramencionada licença.

Ao utilizador é apenas permitido o descarregamento para uso pessoal, pelo que o emprego do(s) título(s) descarregado(s) para outro fim, designadamente comercial, carece de autorização do respetivo autor ou editor da obra.

Na medida em que todas as obras da UC Digitalis se encontram protegidas pelo Código do Direito de Autor e Direitos Conexos e demais legislação aplicável, toda a cópia, parcial ou total, deste documento, nos casos em que é legalmente admitida, deverá conter ou fazer-se acompanhar por este aviso.

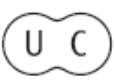




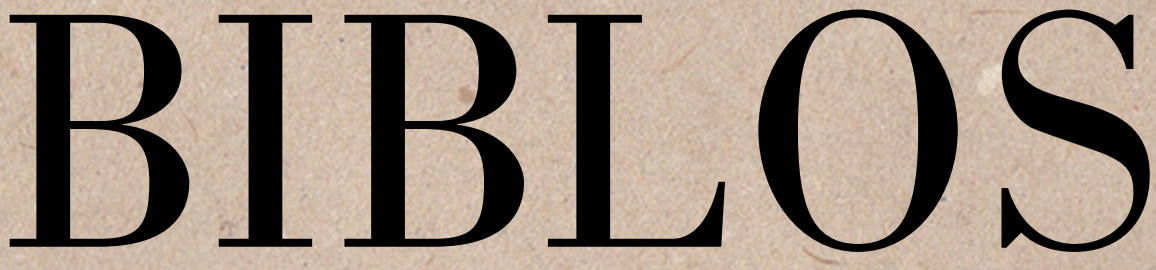

Revista da Faculdade de Letras da Universidade de Coimbra

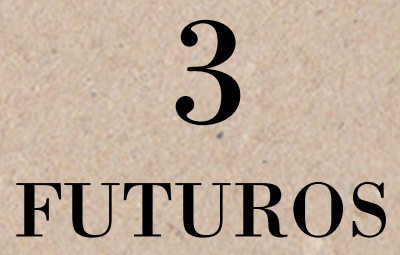

NÚMERO 3, 2017

3. ' SÉRIE 


\title{
UM FUTURO SEMPRE PRESENTE: A CONTINUIDADE DA MISSÁO DA BIBLIOTECA NACIONAL DE PORTUGAL
}

\author{
The future always was \\ there: continuity to the \\ Portuguese National Library's mission
}

\author{
MARIA LUÍSA CABRAL \\ cabral1946@gmail.com
}

Centro de Humanidades, Faculdade de Ciências Sociais

e Humanas da Universidade Nova de Lisboa

DOI

https://doi.org/10.14195/0870-4112_3-3_7

Recebido em setembro de 2016

Aprovado em outubro de 2016

Biblos. Número 3, 2017 • 3. a Série

pp. $149-167$ 


\title{
MARIA LUÍSA CABRAL
}

\section{RESUMO.}

Uma breve visita ao mundo das bibliotecas na Antiguidade revela algumas linhas de força ainda hoje presentes nas bibliotecas. Na Biblioteca Nacional (BNP), com uma vida de mais de duzentos anos, reconhecemos orientação estratégica idêntica. Muito possivelmente a sua responsabilidade institucional, simultaneamente única e insubstituível, assegurou-lhe esta longevidade, através de tempos ora auspiciosos e risonhos, ora deprimentes e descoloridos. A assunção da sua missão identitária, associada à sua resiliência e autonomia, também deve ter pesado. Até que ponto estas características poderão conviver com as exigências e a envolvência de carácter tecnológico? Se a tecnologia se tornar predominante e ditar a iniciativa, entâo, que tipo de bibliotecas sobrará? A construção das colecçôes, para lá da variedade de suportes, é a linha estrutural mais significativa numa biblioteca. O caso da BNP apenas reforça a ideia de que esse elemento estrutural é o garante da continuidade institucional.

Palavras chave: Bibliotecas patrimoniais; Biblioteca Nacional de Portugal; Missão das bibliotecas; Desenvolvimento das colecçóes; Novos suportes da informação.

\begin{abstract}
.
A brief overview of libraries in the Ancient World reveals some trends in libraries today. At the National Library of Portugal, which is over two hundred years old, an identical strategy was followed. Its institutional responsibility, uniqueness and irreplaceable nature, have guaranteed the library's longevity, throughout auspicious and lucky, or depressing and dull times. Undertaking its mission together with its resilience and autonomy must have been decisive as well. To what extent can these characteristics coexist with technological needs and requirements? If technology is to become predominant and is to shape the initiative, what kind of library will be left? Aside from the various types of media, collections development is the main trend in libraries. The case of the National Library only underlines the idea that this core element is most likely the guarantee of its institutional continuity.
\end{abstract}

Keywords: Heritage Libraries; National Library of Portugal; Libraries Mission; Collections Development; New Media. 


\section{INTRODUÇÃO}

Revisitar, mesmo que sumariamente, as bibliotecas da antiguidade ajuda a recordar-nos alguns parâmetros técnicos que, ainda hoje, mantêm a sua centralidade na gestão das bibliotecas. Não se trata de fazer a história das bibliotecas ao longo dos séculos mas apenas de reflectir sobre a longevidade e força de certos procedimentos. É o século XVIII que nos interessa, em particular no contexto português, período no decorrer do qual verificamos o reforço das mesmas preocupações progressivamente adquirindo matizes diferentes. Estes procedimentos ganham tanta ascendência, revelam-se tão insubstituíveis que têm fortes probabilidades de se replicar no futuro. É esta continuidade que tentaremos abordar já que, plausivelmente, esses procedimentos enformarấo o futuro das bibliotecas, situação tâo mais importante de interpretar quando nos debruçamos sobre a biblioteca patrimonial portuguesa por excelência. Entre a afirmação e o sucesso destes procedimentos, a missão da BNP no futuro emana de forma natural, não é arriscado fazer uma previsão.

\section{REUNIR OBRAS E GARANTIR O ACESSO}

Os historiadores das bibliotecas não hesitam em considerar como principais preocupaçóes das bibliotecas os seguintes aspectos: a identificação das obras pelo título; a reunião de obras sobre a mesma temática; a organizaçáo de catálogos. Tudo elementos que surgem como lastro comum desde as mais antigas bibliotecas conhecidas. Todos estes procedimentos, incipientes claro, mas suficientemente explícitos para neles se identificar o genoma da biblioteca como hoje a exigimos. Foi na extensa península da Anatólia dominada pelo Império Hitita (por volta de 1600 A.C.), espraiando-se até ao delta do Tigre e Eufrates na Assíria de Assurbanípal (cerca de 900 A.C.) e, mais tarde, no Egipto dos Ptolomeus (a partir de 300 A.C.) até ao domínio romano (a partir de 50 A.C.) que a arqueologia localizou, reuniu e interpretou testemunhos do que teriam sido as primeiras bibliotecas. A terminologia actual como "título", "obras", "temática" ou "organização de catálogos" deve ser lida e utilizada com infinitas cautelas, sem grandes entusiasmos a não ser os devidos pelo respeito que as civilizaçôes antigas concitam. A Biblioteca de Alexandria, obra 
dos Ptolomeus, obriga a reflectir. A preocupação em reunir obras (isto é, registos em rolos de papiro), sempre muitas cópias e originais quando possível, confere-lhe um cariz distintivo. A "temática" deixou de ser estritamente de carácter administrativo e jurídico - como se infere que acontecia a partir das tabuinhas de argila descobertas por toda a Anatólia - para passar a ser de carácter histórico ou literário. Em Alexandria, a biblioteca atinge outro patamar, supera-se. Deixa de ser apenas o local onde se guardam os testemunhos (ou provas constituindo, quiçá, um arquivo) mas torna-se o local onde se conservam, de forma ordenada e organizada, os originais ou as cópias de obras, em rolos devidamente identificados, cujo principal destino já é a fruição. No seu conjunto, um processo em contínuo, cumulativo como Casson (2002) ou Dahl (1972) argutamente descrevem.

Reunir para ter disponível, para oferecer, uma necessidade que recua aos primórdios da História. Na Grécia e em Roma, as bibliotecas modificam-se no seu conteúdo e na sua abrangência. Também na sua visão e ambição. Continuam a ser fiéis depositárias da memória mas há uma alteração profunda de paradigma. Enorme mutação, precisamente com a Grécia, do paradigma custodial para o lúdico e identitário. Serâo precisos muitos séculos para afinar bem estes novos conceitos de referência e traçar de forma inequívoca as linhas que separam e distinguem arquivos de bibliotecas mas o primeiro passo estava ensaiado. E sendo lúdica e identitária, a biblioteca proporciona a leitura de poetas que relatam a saga marítima; ou historiadores que narram momentos gloriosos; ou dramaturgos que aplicando códigos distintos narram as dores e as alegrias dos povos. Reunir, organizar para facilitar o acesso, corresponder à procura e atender os leitores fossem eles quais fossem. O fio condutor (Casson 2002) prossegue muito para além do Mundo Antigo. Ao referir a facilidade no acesso ou a pressão dos leitores, então, a arrumação dos livros, a sua disposiçấo nas estantes, a colocação destas em vastos salōes, constituirá uma problemática em aberto, século após século: quando se arrumam os livros o que se pretende? A óbvia arrumaçấo física ou a disponibilizaçấo de uma chave para penetrar no âmago dos livros, do conhecimento? Uma questão fulcral a que a Real Biblioteca Pública da Corte não ficará imune. 
As bibliotecas de Setecentos apenas constituem mais uma etapa no longuíssimo processo de organizaçáo das bibliotecas, um caminho recheado de etapas vitoriosas. Num tempo em que o saber assume um lugar de destaque entre as preocupaçôes sociais, não se passa nada de substancialmente diferente com as bibliotecas setecentistas seja onde for, centro ou sul da Europa, ou na novíssima América. Na vastidão desta realidade, a história da Real Biblioteca Pública da Corte, fundada em 1796, não constitui excepção. Os criadores da Real Biblioteca, seja Frei Manuel do Cenáculo (1724-1814), ou o Doutor António Ribeiro dos Santos (1745-1818) ou mesmo o Ministro da Fazenda D. Rodrigo de Sousa Coutinho (1755-1812), empenharam-se de forma diversa, na busca e reuniâo de obras, na organização da sua acessibilidade. Tratou-se de um período tâo notável como decisivo para a Real Biblioteca em grande parte interpretado por Ribeiro dos Santos, figura a que voltaremos. Se a opçáo pela reuniáo de obras - expressa aqui da forma mais despojada possível - deixar de constituir um dos pilares em torno dos quais se desenvolve(m) a(s) actividade(s) $\mathrm{da}(\mathrm{s})$ biblioteca(s), justificando-a(s), então, nada se reteve das liçôes do passado e a missão da(s) biblioteca(s) será outra, não a expectável.

\section{CONSTITUIR COLECÇÓES. ENRIQUECER}

\section{E ALARGAR O CONHECIMENTO. IR MAIS LONGE}

O conceito de colecção está no cerne da biblioteca. Vem da Antiguidade, repete-se pelos tempos modernos. Apesar do debate que provoca, no dia a dia das bibliotecas o problema não se resume apenas à percepção. Ou seja, muito para além da vontade ou do entendimento sobre a centralidade das colecçôes, a dificuldade em dispor de colecçóes consiste na garantia da sua consistência, na manutenção dessa orientação, transferindo para um conjunto de livros a responsabilidade dele se transformar na coluna vertebral da biblioteca. Coloquemonos na actualidade. Náo se vai à biblioteca à procura do que conhecemos mas do desconhecido, movidos pela vontade de aprender e descobrir. "A principal função da biblioteca [...] é de descobrir livros de cuja existência não se suspeitava e que, todavia, se revelam extremamente importantes para nós" (Eco 1983: 29). Cruzar as portas da biblioteca deveria corresponder sempre como que à partida 
para outra galáxia, com expectativa e alegria. "Converter a biblioteca numa aventura”, palavras poéticas, sim, mas sábias, muito sábias (Eco 1983: 32)1. Não pode haver dor na busca da informaçáo seja ela percorrendo as estantes, percebendo a relaçáo que existe entre um título e um outro arrumado metros adiante ou explorando uma base de dados bibliográficos. A satisfação pela pesquisa, concretizada no contacto físico com os livros ao longo das prateleiras ou conseguida pela rapidez e eficácia virtuais, correspondem a objectivos diversos, a perfis de utilizadores diferentes, a formaçóes com origens várias. Todos táo distintos quanto o são o tipo de biblioteca muito embora com um denominador comum: se o utilizador náo encontrar respostas às suas questóes, se este vazio se repetir e se tornar ele próprio a resposta, entáo é inevitável que o utilizador questione o interesse daquela biblioteca, os seus fins e missão. Para que serve afinal uma biblioteca se náo contribui para a descoberta do presente e do futuro? Esta é a interrogação que nenhum profissional de biblioteca, seja um técnico seja um gestor, quer ouvir. Será que uns e outros têm feito o suficiente para a evitar?

Nenhuma colecção se constrói ao acaso, com os altos e baixos do compra e do não-compra, muito menos do pé para a mão. Dispor de colecçôes coerentes e sólidas exige sistematização, classificação, uma escala de valores. Tudo começa pela selecção de obras a adquirir. A selecção obriga ao domínio das fontes de referência, da bibliografia da especialidade mas exige também a vontade de partilhar recursos, a disponibilizaçáo do que existe evitando as duplicaçóes entre bibliotecas. Quem faz a selecção, quem sugere esta ou aquela aquisição tem de conhecer razoavelmente a área temática, as respectivas instituiçóes de ponta, nacionais ou estrangeiras, os autores quer os clássicos quer os que vão chegando. Por outras palavras, quem sugere aquisiçôes deve possuir um conhecimento focado e estruturado. A constituição de colecçôes caracteriza-se por uma rota sem oscilaçôes, sempre na senda do que melhor se faz, se discute e se publica numa determinada área. Em consequência, à medida que as fontes se diversificam e que os suportes se multiplicam, a funçấo torna-se cada vez mais

1 Tempo verbal alterado. 
complexa e exigente. Uma das questôes técnicas mais sensíveis empoladas por esta diversidade de suportes prende-se com o controlo bibliográfico. Este sim, é um problema, não a diversidade de suportes. Numa palavra, ou se estuga o passo ou a globalizaçáo ganha o desafio.

As colecçôes constituem-se ao longo de anos, de décadas e a sua consistência torna-se o pilar da própria biblioteca. Procura-se uma determinada biblioteca porque ela ganhou nome na determinaçáo com que se apetrechou numa temática específica. Sabemos que ao cruzar a soleira dessa biblioteca, sem dúvida uma biblioteca de referência, encontraremos resposta para a investigação em curso e essa certeza compensa todas e quaisquer dificuldades sentidas até aí. Tudo gira à volta da forma de como conseguir construir a colecção e a resposta não é óbvia. Numa instituição, a solução não depende da vontade individual; a notoriedade da instituição, os créditos que soube acumular, o seu bom desempenho, são elementos que lhe proporcionarão os meios, logo, abriráo o caminho para responder ao como. A organização que uma biblioteca configura não vive de doaçôes ou ofertas ou de qualquer outro subterfúgio legal ${ }^{2}$. A entrada de um novo título é sempre bem-vinda apesar dos procedimentos e normas que exige (situaçôes que deliberadamente não abordaremos) mas o enriquecimento de uma biblioteca alcança-se através de um plano de aquisiçóes ao longo da vida institucional, ano após ano, de forma estruturada. É impensável, pois, dispor de verbas um ano para perder nos seguintes qualquer capacidade financeira. A actividade editorial não pára; pode vacilar, pode avolumar-se ou sofrer reduçáo, mas prossegue. O público adquire, as instituiçôes também. Se as bibliotecas não comprarem quando se publica, já não o farão porque se torna muito difícil encontrar os títulos para não referir os valores que podem atingir. Um princípio inexorável como o ciclo de vida. Uma vez adquiridos, os livros podem acumular-se em pilhas até ao tecto, em longas filas de espera, como acontece em tantas bibliotecas pela Europa ou pelos Estados Unidos - e que alegria para

\footnotetext{
2 Em Portugal, a prática do depósito legal é regida pelo Dec. Lei 74/82, 3 de Março, o qual tem alimentado muitas bibliotecas transformando o que prometia constituir um factor positivo num entrave maior ao pleno desenvolvimento daquelas, razão que justifica a revisão do diploma.
} 
um bibliotecário! - mas entraram (terminologia técnica muito própria), logo, serão tratados. Cada coisa a seu tempo. Aliás, se os procedimentos forem os adequados, rapidamente a notícia da sua existência será disponibilizada para satisfaçáo e tranquilidade dos leitores. As bibliotecas precisam de verbas constantes e regulares. O Estado dispóe de uma biblioteca nacional? Não poderá, então, ignorar a obrigação de assegurar uma verba razoável e constante para aquisição de bibliografia. O próprio sistema encarregar-se-á, mais tarde, de avaliar a oportunidade das opções feitas, da política de aquisições executada.

Não há como negar que o problema do enriquecimento de uma biblioteca comporta uma fortíssima componente financeira. Registe-se, porém, que a regularidade dessa componente importa mais que o montante. Como quem levanta uma parede, tijolo a tijolo, também as colecçôes, título a título, ganham forma, conquistam o seu espaço no universo do saber. Este objectivo, feito preocupação, revela-se fundamental porque é de conhecimento que tratamos. Pensando na situação de forma positiva, é a gestão do conhecimento que está em causa. As bibliotecas contribuem para este crescendo do conhecimento e, plausivelmente, é isso que as transforma em locais tão especiais. Nesse percurso, há o antes e o depois, ambos a definirem-se com tempos próprios. As bibliotecas para se manterem vivas, náo podem deixar de acompanhar estes tempos. Os ingredientes são a perseverança, os anos, as verbas. As instituiçóes sabem bem que é a alocação anual das verbas que assegura o investimento no conhecimento e na cultura embora nem sempre pratiquem.

A riqueza das colecçóes revela-se, em grande parte, pela acumulação e guarda do conhecimento passado. Perante as mudanças em curso cuja origem imputamos, largamente, às alteraçôes tecnológicas, a composição das colecçôes está a sofrer transformaçōes profundas. O papel, fiel companheiro e testemunha desde o século VIII ${ }^{3}$ a partir do Próximo Oriente (Dahl 1972), deixou de ser o suporte-rei e pese embora continue a ocupar um lugar muito significativo, a verdade é que o suporte electrónico não pode ser descartado exigindo, também

3 Deixamos de parte a China onde há testemunhos sobre a existência do papel desde os séculos II-III D.C. 
ele na sua identidade como documento, ser selecionado, incorporado, tratado e guardado. A dicotomia suporte papel versus electrónico instalou-se e marca as nossas vidas. Visual ou sonoro, pouco importa. As bibliotecas continuarão com certeza a guardar obras impressas e manuscritas em papel e pergaminho ${ }^{4}$, cumprindo uma tradição com milhares de anos, mas terão de acrescentar a identificação (contribuindo para o controlo bibliográfico) e salvaguarda de novas fontes e suportes de informação que surgem a uma velocidade fora de controlo, para lá dos circuitos habituais, interagindo com o estabelecido há décadas, ou séculos, criando uma espiral de conhecimento que exige a todo o custo ser tratada e guardada. Dispor de colecçóes, independentemente da temática, dimensão, formato ou suporte, requer muita disponibilidade, formação específica, muito espaço de armazenagem, seja físico seja virtual. O figurino da colecção mudou, acompanha as propostas tecnológicas, qualquer paragem equivale a um retrocesso mas, na essência, a colecção continua a corporizar o que de mais seguro se pode esperar - e exigir - da biblioteca. Palpável ou virtual, a informaçáo conflui para a biblioteca concretizando uma complementaridade que subjaz à sua missão. No século XVIII era o papel, com certeza, mas a sensibilidade para a novidade estava presente. Com a tecnologia da época, a novidade cingia-se à impressão de qualidade, envolvendo o papel e os tipos metálicos. À sua medida, a tecnologia impunha-se. No tempo de Ribeiro dos Santos, em 1802, a aquisição de cento e noventa e sete volumes das ediçôes Bodoni ${ }^{5}$ para a Real Biblioteca reflectem claramente essa atenção e predisposição. Independentemente do suporte e da variedade, o que engrandece a biblioteca é a reunião sistematizada da informação.

4 Excluímos outros suportes da escrita mais comuns fora da Europa.

5 Giambattista Bodoni (1740-1813), impressor régio em Parma, notabilizou-se pela qualidade técnica da impressōes na dupla vertente dos tipos usados e da qualidade de papel selecionado, resultando num trabalho de finíssima qualidade a justificar, na opinião de D. Rodrigo de Sousa Coutinho, "[...] que S.A.R., o Príncipe N.S. enriquecesse a sua Real Biblioteca com as outras ediçóes de Bodoni [...]”, uma alusão directa à aquisição que se concretizaria (Cabral 2014: 313). 


\section{UMA BIBLIOTECA NÂO É UMA LIVRARIA. TAMBÉM NÁO É UM ARMAZÉM}

Uma biblioteca não abarca tudo, não compra tudo, muito menos abre os braços a qualquer doação. As doaçóes, aliás, sáo sempre motivo de desconfiança e devem ser escrupulosamente avaliadas antes da concretização, clarificando as condições em que serão aceites. A biblioteca adquire e compra de forma criteriosa mas não lhe basta ter uma prática negocial correcta ainda que seja particularmente importante o contacto com o exterior. A biblioteca mostra-se para o exterior para que se saiba, claro, que a biblioteca tem objectivos específicos mas também para que conste que a biblioteca definiu uma linha temática que quer ver desenvolvida e prosseguida. Valorize o mercado ou não, a biblioteca também age com paciência e aguarda. Náo actua pelo interesse imediato e materialista do ganho. Identificamos aí os aspectos que a distinguem de uma livraria. Não faz sentido entrar numa biblioteca convencidos de que encontraremos tudo o que existe porque mesmo numa boa livraria isso não acontece. Nem se encontram todas as temáticas, nem todos os autores nem se encontram os títulos mais díspares. É esta uma das razōes pelas quais a lei portuguesa do depósito legal deve ser revista. São onze as bibliotecas portuguesas que recebem o depósito legal e o pacote é igualzinho, do bom ao muito mau distribuindo equitativamente as lacunas. Falta aqui algum equilíbrio o qual, uma vez reposto, náo impedirá que a biblioteca patrimonial por excelência continue a receber e a guardar tudo, assumindo a sua responsabilidade como repositório bibliográfico nacional. A sobrevivência e as leis do mercado obrigam uma livraria a ser ecléctica mas mesmo assim essa montra tem limites. Os princípios que regem uma biblioteca seguem outro código à cabeça do qual não se identifica a preocupação com o lucro imediato, no curto prazo. As bibliotecas demonstrarão que alcançaram lucro, sim, num modo mais tranquilo, sob a forma de aquisiçáo e difusão de conhecimento.

Apesar da grande variedade de títulos, uma biblioteca também não é um armazém. Num armazém, as ediçóes e os títulos, incondicionalmente empacotados, amontoam-se e a sua organizaçấo como estoque espraiado por estantes e por editoras, identificável apenas por um número de remessa, a eito. As obras, arrumadas segundo critérios comerciais e tendo também em conta o espaço disponível interdito ao público. Claro, sem público, nada mais antagónico ao espírito de uma biblioteca. 
Entre estes três tipos de depósito de livros, é na biblioteca que se espera encontrar coerência e permanência temáticas. A biblioteca significa o lugar que não se altera ao sabor da ocasiáo; antes, o lugar preocupado em guardar e preservar. Mesmo quando uma determinada temática não tem grande procura, a biblioteca assegura que, hoje e no futuro, a informação resiste. Os catálogos são continuadamente alimentados. Esta fiabilidade transforma a biblioteca num local inigualável. A noção desta responsabilidade explica as preocupações com a arrumação, limpeza e conservação dos documentos. No caso português, preocupaçóes amplamente documentadas (Bandeira 1995: 79-105). Duas grandes figuras centrais na construção de bibliotecas no Portugal de Setecentos deixaram o seu testemunho nesta matéria. Um dos primeiros contactos de Cenáculo com bibliotecas aconteceu quando foi encarregue da limpeza da Livraria do Convento de Jesus (Lisboa) "[...] a cuja arrumação eu servi, sendo Corista em o ano de quarenta, em que também me encarregaram do asseio da casa [...]" (Cenáculo 1794: 196) ou "[...] tive a sorte de trabalhar na distribuiçáo daqueles livros [...] e logo se me encarregou a limpeza da livraria [...]" (Cenáculo 1844: 144). Do mesmo modo, Ribeiro dos Santos bem se preocupou com o estado de conservação dos livros na Mesa Censória "Uma parte desta biblioteca está colocada em algumas estantes, outra está lançada ao montão no pavimento das casas [...]" (Santos 1795: Estado da Biblioteca, 1o \$).

\section{A RESPONSABILIDADE PATRIMONIAL DAS BIBLIOTECAS}

Quando as bibliotecas têm uma responsabilidade patrimonial isto significa que há núcleos das suas colecçóes que não podem ser, sob que pretexto for, alienados. Os critérios para definir esse património são definidos e articulados em cada biblioteca promovendo uma cooperação e partilha com outras bibliotecas de considerável peso; o contrário denunciaria um grande absurdo. Não parece que haja bibliotecas que se possam eximir a essa preocupação intrínseca à qualidade de biblioteca. As bibliotecas reúnem conhecimento passado, especializaram-se em gerir essa informação acumulada. Ora, muita dessa informaçáo adquire o estatuto de património e, como tal, vai ter de ser preservado. O património muitas vezes prende-se directamente com a questão identitária o que também não é exclusivo 
das designadas grandes bibliotecas e a fundamentar esta afirmação basta remeter para muitas bibliotecas municipais com colecções ricas e únicas de interesse local das quais, aliás, são muito ciosas. No entanto, o facto de existirem fundos patrimoniais náo outorga, linearmente, o título de patrimonial. Uma biblioteca municipal com um núcleo de interesse local, por maior que este possa ter, não adquire o estatuto de biblioteca patrimonial; antes de mais nada, ela é uma biblioteca municipal, a sua missão prende-se com esta qualidade, não com outra qualquer. Na verdade, em relação ao universo das bibliotecas patrimoniais, o número é escasso. As suas responsabilidades são enormes, prolongam-se no tempo, determinam o tipo de gestâo e, sobretudo, a sua relação com o público. Por regra u ma biblioteca patrimonial é uma biblioteca de conservação, o público por muito escrutinado que seja náo tem acesso directo às estantes. No caso de uma biblioteca apenas com um ou outro núcleo patrimonial, estes estáo à parte, reservados. Verdadeiramente uma biblioteca patrimonial é aquela em que todo o seu acervo goza dessa designação e, nessa circunstância, as bibliotecas nacionais estão na primeira linha. O repositório bibliográfico nacional à sua guarda é, no seu conjunto, inalienável. As bibliotecas não se constituem à revelia do seu tempo; os documentos que guardam constituem memória de um tempo. É por esta via que umas bibliotecas são patrimoniais, outras não. Esta consciência sobre a razão de ser da biblioteca vai ganhando raízes, e da reuniáo abundante e menos sistematizada passará, mais tarde, a um pensamento estruturado e a uma intervenção dirigida. Nalguns países europeus mais cedo do que noutros, em Portugal assistimos a esta transformaçáo no final do século XVIII: de um lado, a Livraria da Mesa Censória descrita e apresentada por Ribeiro dos Santos no Relatório sobre o Estado da Biblioteca da Real Mesa Censória em 1795, enquanto, do outro lado, o trabalho de conceptualizaçáo e estruturação que o mesmo Ribeiro dos Santos vai aprontando para acolher as aquisiçóes destinadas à Real Biblioteca Pública. Sobre a inexistência de sistematização na Livraria da Mesa Censória, escreve Ribeiro dos Santos: "[...] os livros que ocupam as estantes estão colocados não metodicamente [...] mas sim promiscuamente e sem algum sistema [...]" (Santos 1795: Estado da Biblioteca, $1^{\circ}$ \$). A sistematizaçáo introduzida na Real Biblioteca e amplamente revelada 
nos seus códices ${ }^{6}$ confere à Real Biblioteca uma responsabilidade única, trabalho imprescindível naquele momento de organização inicial, enquanto lhe dita o futuro e a coloca na modernidade.

\section{O TEMPO E O LUGAR DE UMA BIBLIOTECA PATRIMONIAL}

É difícil defender que em 1796 o conceito de repositório bibliográfico nacional existisse e estivesse firmemente burilado. Não se pode extrair essa ideia a partir da análise dos códices de Ribeiro dos Santos. Contudo, sobram argumentos reveladores da sua preocupaçâo em adquirir bibliografia tấo recente quanto lhe era possível no sentido de criar, na Real Biblioteca, um recurso bibliográfico de reconhecida qualidade. Sempre com a manifesta intençáo de defender a história e língua portuguesas ora com relatórios ora com estudos de carácter vário em prol dos autores portugueses como Sá de Miranda ou António Ferreira amiúde citados. A Real Biblioteca náo se assumia ainda como um verdadeiro repositório; a relação entre impressores e a Real Biblioteca, nos primórdios do que viria a ser a prática do depósito legal, há-de chegar ${ }^{7}$ apesar da preocupação com a riqueza das colecçôes expressa anteriormente por D. Maria no diploma que cria a Real Biblioteca ${ }^{8}$ ou de uma instrução assinada a 8 de Junho de 1798 pelo Marquês Mordomo Mor (inspirada sem dúvida por Ribeiro dos Santos) dirigida a Miguel Manescal da Costa para que fosse remetido para a Real Biblioteca Pública "[...] hum exemplar de cada huma das obras que se tiverem imprimido na Regia Oficina Tipografica, e ainda nela existirem” (BNP AHBN CR/03/Cx. 01/Doc. 01, f. 11).

Medidas ou manifestações de intenção, o círculo ia-se apertando e a Real Biblioteca ganhava um lugar central. Justificava o local onde estava instalada, paredes meias com os órgãos do poder. Só podemos concluir que esta articulação

\footnotetext{
${ }^{6}$ Sáo muitos os exemplos presentes nos códices de Ribeiro dos Santos. BNP COD. 4583-4732 (Cabral 2014: 258 e ss.).

7 Alvará de 12 de Setembro de 1805.

8 Alvará de 29 de Fevereiro de 1796.
} 
não foi obra do acaso: com o prestígio da localização, chegam as preocupaçôes em dotar aquela biblioteca de recursos bibliográficos do seu tempo o que, tudo junto, projecta a Real Biblioteca para outro patamar. Gradualmente, a Real Biblioteca adquire os vectores que a distinguem de outras. Por vezes de forma incipiente mas sempre no mesmo sentido, mantendo igual empenho. Quem a dirigiu nesses anos iniciais terá gozado da proteção decisiva da Corte, soube movimentar-se nos meandros necessários para ganhar um espaço e afirmar um projecto que náo conheceria retorno. Os anos que Ribeiro dos Santos dedicou à Real Biblioteca, entre 1796-1816, colocaram definitivamente a Real Biblioteca na ribalta.

\section{A BIBLIOTECA PATRIMONIAL COMO LUGAR DE CHEGADA E DE PARTIDA}

Sobre a biblioteca patrimonial recai uma enorme responsabilidade. Táo grande quanto a expectativa que alimenta. Acumula o repositório bibliográfico de um determinado país ou nação; tem à sua guarda tesouros nacionais que, naturalmente, emanam do repositório; obriga-se a registá-los contribuindo para o controlo bibliográfico; a conservá-los nas melhores condiçôes possíveis; a estudá-los e divulgá-los. Nada de somenos. Para a biblioteca patrimonial confluem por via legislativa exemplares da produçáo impressa nacional mas esta corresponde a uma função passiva. É a instituição na sua capacidade receptora, o lugar de chegada. Acumula, trata, guarda. Todas estas fases da tarefa não podem ser consideradas menores. Como um compasso de espera para um tempo que chegará. Esse momento de futuro prende-se, entáo, com a exploração que os próprios fundos proporcionam e, de alguma maneira, abre-se a porta para o desconhecido. Um tempo para construir as inter relaçóes nem sempre óbvias entre os documentos existentes ou entre estes e outros que afanosamente se podem identificar fora daquela biblioteca. Inicia-se, assim, um processo em espiral tanto mais rico e surpreendente quanto maior e mais arguta for a capacidade daqueles que sobre o repositório reflectirem. Um repositório impresso evidentemente mas também manuscrito e, hoje, virtual. Três camadas interactivas e complementares. Um momento de metamorfose em que a biblioteca se veste de grande criatividade, indicando novos caminhos, orientando a investigaçáo para novas áreas, explorando 
as sugestóes que o material sobre a mesa de trabalho lhe oferece. Esta actividade intensa pode manifestar-se pela adopção de figurino "editorial" mas também, e cada vez mais, pela opção "exposiçóes”. Subitamente, a biblioteca torna-se o lugar de partida. Entre uma atitude mais passiva e uma outra mais activa, a linha de fronteira é ténue mas resistente. A diferença que persiste entre as bibliotecas no seu conjunto e a biblioteca patrimonial é que esta, sem dúvida, disponibiliza recursos mais selecionados, mais diversos e também mais representativos possibilitando uma visão mais abrangente e rica, logo, mais enriquecedora. A transposição da sistematização do saber para o interior da Real Biblioteca que Ribeiro dos Santos denodadamente ensaiou correspondia muito mais do que à simples organização da biblioteca. Nunca seria um trabalho sem escolhos tendo-se tornado uma tarefa muito complexa porque abriu a biblioteca ao futuro. A sistematização do saber com o seu carácter universal trouxe para o cerne da biblioteca uma faceta intemporal, valorizando as colecçóes e maximizando as ambiçóes da própria biblioteca. A articulação das colecções por um lado, e a forma como se pensou na sua reunião e organização por outro, contribuiu de forma inequívoca para fortalecer o carácter patrimonialista da instituição. Não foi sem motivo que Ribeiro dos Santos se referiu aos livros que encontrou na Mesa Censória como um "montão". O que ele ambicionava estava nos antípodas deste cenário.

\section{A REAL BIBLIOTECA COMO BIBLIOTECA PATRIMONIAL}

O Doutor António Ribeiro dos Santos era bibliotecário na Universidade de Coimbra onde desenvolvia um trabalho muito relevante quando foi chamado a Lisboa nos anos 90 de Setecentos. A sua actividade também se estendia a outras áreas e a Corte reconhecia-lhe mérito e fiabilidade. Tão grande a confiança que, a 3 de Janeiro de 1795, é nomeado para assumir a responsabilidade da biblioteca da Real Mesa Censória cabendo-lhe analisar a situação e propor uma solução?

\footnotetext{
9 Frei Manuel do Cenáculo foi o seu mais notável responsável. Porém, desde 1777, encontrava-se em Beja no exercício do seu bispado e politicamente afastado da corte. Convém assinalar este ponto de encontro entre as duas figuras, uma coincidência que tem tanto de interessante como de inesperado.
} 
Não está escrito que se tratava ali de dar início ao processo de organização da Real Biblioteca mas hoje podemos perguntar se essa explicitaçáo teria sido mesmo necessária. Náo, náo era preciso e hoje sabemos como nada aconteceu por acaso. No Relatório sobre o que encontra, considera "[...] o que já é um grande fundo para servir ao estabelecimento da Real Biblioteca Pública da Corte" (Santos 1795: Estado da Biblioteca, 20 \$). Um curto apontamento no Relatório de enorme importância revelando opçóes discutidas nos corredores do poder. Na sua nomeação para Bibliotecário Mor escondia-se uma vontade e um projecto os quais, aliás, se adivinham sob o ritmo acelerado dos acontecimentos. Apenas dois dias depois da nomeação, a 5 de Janeiro, Ribeiro dos Santos apresenta o seu Relatório absolutamente demolidor perante o estado caótico com que se defrontou na Mesa Censória fossem as instalaçóes, os livros, a ausência de catálogos, as faltas. Uma situação que urge remediar sentindo como imperioso "Mandar formar os diversos catálogos [...] não só para servirem ao diante ao uso público da mesma Biblioteca com as adiçóes dos novos provimentos que se forem fazendo mas também para se poder compreender exatamente o fundo capital de livros que esta tem em cada uma daquelas classes, e o que lhes falta ainda para seu inteiro estabelecimento e melhoramento" (Santos 1795: Providências 50 \$). Pela minúcia, estrutura e rigor, é absolutamente improvável que o Relatório tivesse sido escrito no espaço de tempo entre a sua nomeação e a apresentação do Relatório; ou seja, Ribeiro dos Santos já conhecia a situação mas a nomeaçáo assumia-se como indispensável para legitimar a intervenção que se seguiu. Começam, então, os trabalhos conducentes à criação da Real Biblioteca que culminam com o Alvará de 29 de Fevereiro de 1796 fundando a Real Biblioteca Pública da Corte seguindo-se a imediata nomeaçáo de Ribeiro dos Santos como seu director a 4 de Março de 1796. Naturalmente, seguem-se a projecção do espaço físico da biblioteca, os trabalhos para erguer a biblioteca, a reflexáo sobre as colecçôes quer na vertente do seu enriquecimento e actualização quer na da sua organização. Durante uns anos, os contactos com Frei Manuel do Cenáculo a propósito da entrega de obras por parte deste à Real Biblioteca, constitui outro capítulo fundamental na história da biblioteca (Cabral 2014: 165-205) colocando as duas figuras em paralelo no tocante à intervenção e 
responsabilidade na construção da Real Biblioteca ${ }^{10}$. Mas, talvez, este processo não tivesse atingido o brilho que lhe reconhecemos sem a participação e acompanhamento do Ministro da Fazenda e Inspector Geral da Real Biblioteca Pública da Corte, D. Rodrigo de Sousa Coutinho, a quem cabia a tutela da Real Biblioteca e cuja parceria com Ribeiro dos Santos, numa dinâmica imparável, contribuiu de forma inquestionável para a aquisição de bibliografia actualizada ${ }^{11}$. Não soa como excessivo equiparar as duas intervençôes e sublinhar esta parceria pela importância que assumiram na valorização da Real Biblioteca.

\section{O FUTURO DA BIBLIOTECA PATRIMONIAL}

Outras bibliotecas portuguesas durante o século XVIII tornaram-se famosas mercê da atençáo de que foram alvo por parte do poder régio que as distinguiu com massiva aquisiçáo de obras. Encontram-se neste grupo, para além da Real Biblioteca, a Biblioteca Joanina da Universidade de Coimbra, a Biblioteca do Convento de Mafra, a Biblioteca da Congregação do Oratório (Lisboa). De tal forma bem apetrechadas que, sem favor, são merecedoras da designação de um "significativo quadrilátero estratégico" (Pimentel 2009: 18). Sem desmerecer o lugar de cada uma, cabe à Real Biblioteca destacar-se. Porque lucrou com a proximidade do poder central; porque continuou a adquirir bibliografia; porque procurou comprar bibliografia actualizada; porque beneficiou com legislaçáo que lhe ia encaminhando a produçáo impressa nacional; porque foi constituindo o repositório nacional apesar de lacunas constantes; porque foi

\footnotetext{
${ }^{10}$ A leitura de toda a correspondência trocada entre Cenáculo e Ribeiro dos Santos, sem esquecer os intermediários, num total de setenta e uma cartas escritas entre 1 de Fevereiro de 1780 e 21 de Maio de1808, reflecte um momento muito significativo da vida institucional enquanto revela o carácter das duas personalidades (Cabral 2014: 399-508).

${ }^{11}$ Ribeiro dos Santos, com o apoio de Sousa Coutinho, recorreu a diplomatas e comerciantes portugueses colocados na Europa para adquirir bibliografia, actividade documentada no núcleo Correspondência literária e bibliográfica do Arquivo Histórico da BNP DGA/03/Cx02 (Cabral 2014: 283 ss.)
} 
ganhando doadores e mecenas. Este constante enriquecimento, apesar de momentos mais apagados quer no século XIX quer no século XX, tornou-se um eixo fundamental da sua organização e gestão. A chegada tumultuosa de carroças carregadas de livros provenientes de acervos religiosos, consumando as incorporaçôes depois de 1834, não facilitou a sistematização. Mas, como referido anteriormente, uma vez entrados, chegaria o dia do seu tratamento e conhecimento. Esta é uma linha de força indelével: a expansão permanente, o enriquecimento constante. Sem adiamentos ou hesitaçóes. Tratou-se sempre de manter o mesmo nível de desenvolvimento, hoje táo assediado por outros suportes. Náo será a variedade de suportes a alterar o percurso da Biblioteca Nacional embora o desafio tecnológico a obrigue a maior sofisticação quer para a pesquisa quer para o tratamento, nomeadamente a questáo do controlo bibliográfico e armazenamento. Verdadeiramente, a missão da Biblioteca Nacional parece assentar numa articulação bem oleada entre, por um lado, a actualização permanente das colecçôes, enriquecendo o repositório impresso, colmatando lacunas, completando os núcleos impressos com os manuscritos que os valorizam e, por outro, a integraçáo de uma forma criteriosa mas abrangente da informaçáo que circula em modo virtual. Apesar da informaçáo ter deixado de se limitar ao papel, a missáo da biblioteca continua a ser a sua reunião e difusão. A tecnologia, hoje uma, amanhã outra, mas sempre passageira. Exceptuando as colecçóes, tudo o mais é instrumental e transitório.

Os momentos mais auspiciosos da biblioteca portuguesa patrimonial por excelência aconteceram nos momentos de entrada de muitos livros. Em 1836 a massa documental foi largamente superior ao que aconteceu entre 1796 e 1816, quando Ribeiro dos Santos deixa a Real Biblioteca. Para além dos muitos livros entâo conseguidos, o que caracteriza este período é o cuidado e empenho colocado na selecção e classificação de obras, trabalho ímpar. Dois momentos assinaláveis para a história da instituiçáo a que podíamos juntar outros idênticos sempre a consubstanciarem a mesma opção de fundo. Um caminho e uma missão que se confundem a olhar o futuro. 


\section{BIBLIOGRAFIA}

Bandeira, Ana Maria Leitão (1995). Pergaminho e papel em Portugal. Tradição e conservação. Lisboa: CELPA / BAD.

Cabral, Maria Luísa (2014). A Real Biblioteca e os seus criadores: em Lisboa, 1755-1803. Lisboa: Biblioteca Nacional de Portugal.

Casson, Lionel (2002). Libraries in the Ancient World. [Boston]: Yale Nota Bene.

Cenáculo, Manuel do (1794). Memorias históricas, e appendix segundo à disposição quarta da colecção das disposiçöes do Superior Provincial para a observância, e estudos da Congregação da Ordem Terceira de S. Francisco. Lisboa: Na Regia Officina Typografica. T. 2.

Cenáculo, Manuel do (1844). "As letras na Ordem Terceira de S. Francisco de Portugal", in Rivara, J. H. da Cunha (org). O Panorama, s. 2, 3, 143-144.

Dahl, Svend (1972). Historia del libro. Madrid: Alianza Editorial.

Eco, Umberto (1983). A biblioteca. Trad. Maria Luísa Rodrigues de Freitas. Lisboa: Difel.

Pimentel, António Filipe (2009). "A Biblioteca da Universidade e os seus espaços”, in Amaral, A. E. Maia do (coord.). Tesouros da Biblioteca Geral da Universidade de Coimbra. Coimbra: Imprensa da Universidade, 11-21.

Santos, António Ribeiro dos (1795). Relatório sobre o Estado da Biblioteca da Real Mesa Censória. Arquivo Histórico da Biblioteca Nacional DGA/04/Liv.01, f. 2-8 (Ms.). 